\title{
MRS BULLETIN Welcomes New Editorial Board Member
}
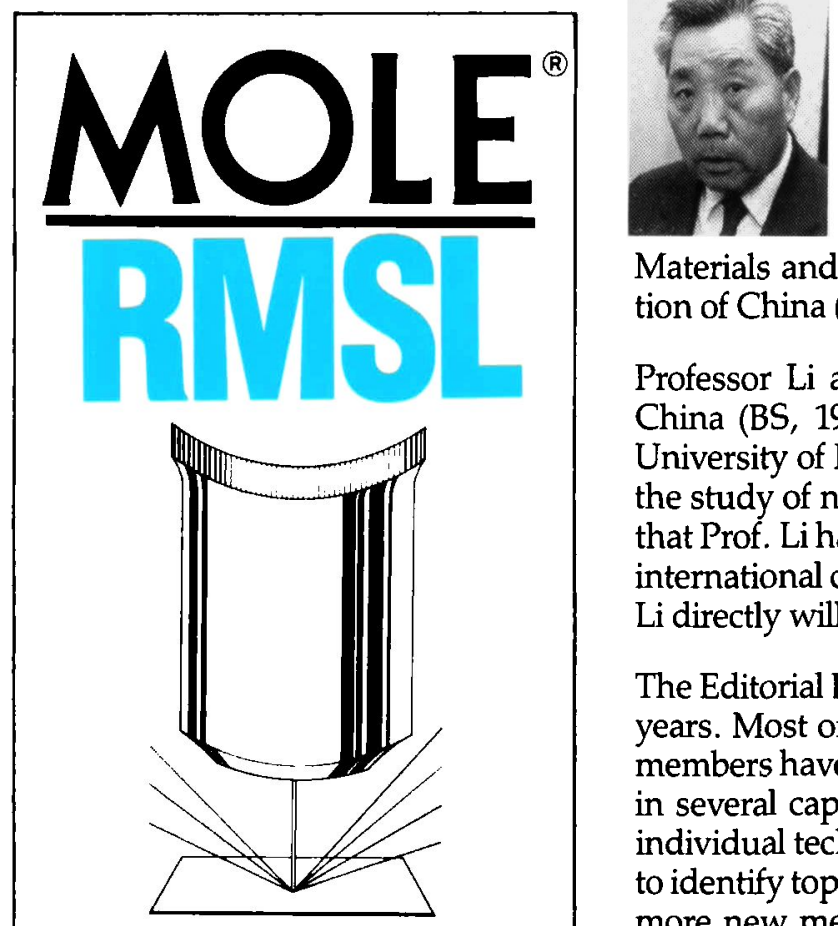

RAMAN MICROPROBE SERVICE LABORATORY THE MOLE ${ }^{\circledast / R M S L ~ F E A T U R E S ~}$ THE MOLE ${ }^{\circledR}$ - U1000 AND $\$ 3000$ RAMAN MICROPROBES FOR COMPLETE MOLECULAR AND CRYSTAL PHASE ANALYSIS:

- $1 \mu \mathrm{m}$ spatial resolution.

- Non-destructive analysis.

- Quality control and failure analysis of organic/inorganic contaminants.

- Feasibility studies

- Fast turnaround.

We have been solving problems in ceramics, polymers, semiconductors $\ldots$ and many other areas for over 10 years.

Contact the Raman application lab for consultation and analysis costs.

JOBIN V J.Y Optical Systems YVON LAA Instruments SA

6 Olsen Avenue, Edison, NJ 08820-2419 (201) 494-8660 Telex 844516 FAX (201) 494-8796

In Europe Jobin Yvon, 16-18 Rue du Canal 91163 Longjumeanu, France - Tel. (33) 1.69.09.34.93

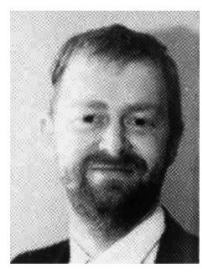
Materials and Engineering Sciences for the National Natural Science Foundation of China (Beijing).

Professor $\mathrm{Li}$ attended the National Northwestern College of Engineering in China (BS, 1942), the Carnegie Institute of Technology (MS, 1947), and the University of Pennsylvania (PhD, 1953). His primary research interests involve the study of nuclear materials and ion beam-solid interactions. MRS is pleased that Prof. Li has consented to help the BULLETIN as it assumes an increasingly international character and readership. Readers who would like to contact Prof. $\mathrm{Li}$ directly will find his address on page 2 of this issue.

The Editorial Board of the MRS BULLETIN has been serving MRS for over four years. Most original members continue to serve to the present and a few new members have been added along the way. The Board has served the BULLETIN in several capacities, acting as book review editors, suggesting and soliciting individual technical articles, providing research community news, and helping to identify topical themes of interest to BULLETIN readers. During 1988, several more new members are expected to join the Board as initial terms of service come to a close, according to Kaufmann.

\section{Boyd Succeeds Golanski as MRS BULLETIN Associate Editor-Europe}

Professor Ian W. Boyd, of the Department of Electronic and Electrical Engineering, University College London, has been named Associate Editor-Europe for the MRS BULLETIN. The position of Associate Editor-Europe was created in 1987 in response to burgeoning materials research activities in Europe and the rapidly growing European Materials Research Society organization, whose members receive the BULLETIN. The Associate EditorEurope role is intended to be filled on a rotating basis from year to year. Dr. Andre Golanski of CNET Grenoble, who, as first Associate Editor-Europe, has been responsible for markedly greater Europe-related content in BULLETIN pages, has shaped an editorial and correspondents resource which will serve the BULLETIN well in future years.

Boyd graduated in physics from Herriot-Watt University (Edinburgh) in 1982 and spent two years at North Texas State University's Center for Applied Quantum Electronics before assuming his current position. His technical interests include laser processing and thin silicon dioxide structures.

The BULLETIN encourages readers in Europe or readers who have specific interests in coverage of European materials research topics and organizations to contact Prof. Boyd directly at the address given on page 2 in this issue. 